\title{
A case study on occupational stressors and effective stress management interventions from a call center perspective
}

\author{
Akanji, Babatunde Oluwatoyin $\triangle$ \\ Elizade University, Nigeria (toyinbabs01@yahoo.com)

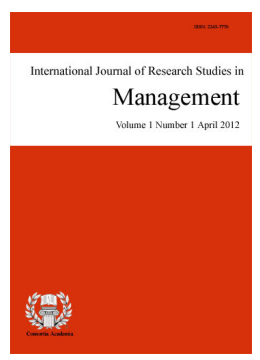

Accepted: 12 February 2016

ISSN: 2243-7770 Online ISSN: 2243-7789

OPEN ACCESS

\section{Abstract}

This case study explores the realities of work stress in the Nigerian call center context and employees' views on how effective stress management practices can improve workplace well-being. A total of 30 participants (20 call center agents and 10 team managers) employed in two different call centers took part in the study. Semi-structured interviews were conducted about the impact of call center working conditions on employee well-being while thematic content analysis was used to analyze the data. The findings unveiled various interpretations of how participants perceived call center stressors and the various coping strategies used in managing job stress. Furthermore, recommendations were made for call center organizations within this context to implement organizational-levelled stress management practices rather making employees indulge in individual coping abilities. Thus, the implication of study is to create a scholarly awareness on how occupational stress is perceived and interventions conceptualized in service jobs within a non-Western context where literature is rare.

Keywords: work stress; Nigerian call center work; stress management practices; call center stressors; non-western context 


\section{A case study on occupational stressors and effective stress management interventions from a call center perspective}

\section{Introduction}

The proliferation of the call center industry has often been accredited to the widespread quest for rapid service deliveries (Mukherjee \& Malhotra, 2006). However, occupational stress has remained a central challenge within most call center milieu (Rasila, 2012). For instance, one main stressor associated with these cost-effective facilities utilized by companies to connect with potential and existing customers is often attributed to the heavy deployment of technology to scrutinize and uniformly control service performances (Choi, Cheong \& Feinberg, 2012). Consequently, diverse research especially undertaken in developed countries have reported extensively on the impact of this tightly controlled systems on employee well-being while developing countries remains under-researched despite the fruitful development of call center stations in these regions (Budhwar, Varma, Malhotra, \& Mukherjee, 2009). Consequently, the importance of addressing customer service working conditions in developing countries is because there is still limited research focus in these regions despite the economic benefits gained by large companies from industrialized economies outsourcing their call center operations and engaging in off-shore customer service activities in these low income countries such as the Philippines, Pakistan and India (Das, Dhawadkar, \& Brandes, 2008). Furthermore, the lucrativeness of the telecommunications business in developing countries of Africa has attracted foreign direct investment from global ICT firms gaining entry into some West African markets in Ghana, Benin republic and Nigeria (Pyramid Research, 2010). However, reports on call center operations in various countries seem to present a broad resemblance of working environment, management practices and job characteristics. Against this backdrop, this paper aims to make valuable contributions by examining the nature of call center stress existing in a context-specific culture by exploring views of call center employees on service systems operationalized in the Nigeria.

It is well known that call centers are operated via integrated telephoning systems. Agents simultaneously use their computers to process, record, update customer data and answer all customer queries in accordance to compliance standards. Office layouts are often open plan with high noise levels from almost all representatives interacting remotely with customers. Call center environments were described in the past by Garson (1988) and Taylor and Bain (1999) as "electronic sweatshops" and "battery hens" with a view of explicating the intensive and challenging nature of the call center profession. Therefore, the aim of this study is to explore the realities of call centers challenging service workers in Nigeria where literature is scarce. It is believed that this paper will be of benefit to mainstream academia through its significant contribution to global call center literature by disseminating novel research information of call center stress from a non-Western context. The study could also be of benefit to welfare professionals and human resources personnel of the various telecoms multinationals in Nigeria and other foreign potential entrants intending to engage in telecommunication business on how employee stress can be effectively managed for better organizational performance. Hence, this paper is structured as follows: the second section examines stress theories and call center stress in literature. Subsequently, the third section presents information about the Nigerian call center industry. The fourth part covers the methodology and approach used to collect data and subsequent analysis of findings and discussions. The lastly, the conclusions, limitations and areas for future research are then presented.

\subsection{Stress theories}

In lay terms, the meaning of 'stress' is often described as feelings of being under too much physical, emotional and mental pressure resulting into strain. But at a conceptual level within various fields of stress research, there has been no consensus as to the definition of workplace (Mark \& Smith, 2008). Historically, 
theoretical debates have conceptualized occupational stress from the stimulus perspective, response-based approach and interactive propositions of a relationship between individuals and their environment that is adversarial to well-being. For instance, the stimulus-based theorists perceive stress as characteristics of the environment that are considered disturbing. Thus, Cox, (1978) argues that the stimulus-based interpretation of stress historically centered on "what happens to the man and not that which happens in him". On the contrary, the response-perspective considers stress from people's biological reactions to stressors. In this school of thought, earlier scientific scholarships by Selye (1974) defined stress as "the non-specific response of the body to any demand upon it". By non-specific response, Selye conceptualized that regardless of whether it is positive (i.e. eustress) or harmful (i.e. distressful) outcomes originating from surrounding stressors, the human bodily responses still undergoes its general metabolic processes for the purposes of either preparing reactive secretions to combat, accommodate or remove such stressors.

However, Vakola and Nikolaou, (2005) argued that more advanced scholarships consolidated both the stimulus and biological response-based definitions by stating that stressful situations mostly occur from people's interactions with their environment in which psychosocial risk factors (i.e. stressors) that results into strain. In addition, Lazarus and Folkman (1984) proposed that stress becomes inevitable when an individual has insufficient resources to cope with situational demands placed on them. When this occurs, an evaluation of the potential risk is initiated (i.e. primary appraisal) which then informs the processes that frames an individual's development of coping strategies (i.e. secondary appraisal) to manage stress. Furthermore, Lazarus and Folkman (1984) proposed problem-focused and emotional-based coping strategies as two major methods used by people to moderate the effects of stressors and strain outcomes. Problem-focused coping behaviors was conceptualized as proactive measures used to reduce or alter distressful conditions whereas emotionally based-approach refers to one's tendency to manage painful emotional reactions in a temperate manner especially when such conflicting challenges cannot be altered or changed momentarily. This theoretical background will be used within the present study to assess how Nigerian agents perceived work stress within the call center context.

\subsection{Call center stress}

A popular call center stress experience is often ascribed to the intensity of emotional labor demands. Morris and Feldman (1996) defined emotional labor as "effort, planning, and control required displaying organizationally desired emotions during interpersonal transaction". According to Hoshchild (1983) who pioneered the concept, explained the intensive nature of managing personal feelings during the execution of customer service labor where organizational prescribed rules of emotional display takes priority over any shred of truly felt emotion. Consequently, the extent of high emotional enactment in call center work that requires continuous expressions of normative emotions whether faked or surface acting have been found in some studies to amplify burnout in form of emotional exhaustion, depersonalization and reduced work accomplishment (Choi, Cheong, \& Feinberg, 2012). Furthermore, Kinman, (2009) found in her quantitative study of 246 front-line employees that the negative impacts of emotional dissonance had a potential spill-over effect into other non-work roles that leads to perceived work-family conflict.

Role stress is also regarded as unpreventable within call center roles (Ackfeldt \& Malhotra, 2012). For instance, customer aggression expressed during conversation with service agents have been identified as one of the primary role stress that substantially impact employee wellbeing. Hostilities such as insults, shouting, derogatory remarks and other forms of vocal aggression vented by customers during telephone conversation are found to positively relate to burnout situations experienced by call center agents (Grandy, Dickter, \& Sin, 2004). Furthermore, Robinson and Morley (2006) argued that most call center managers rather concentrate on mass attendance to customers as a yardstick for measuring productivity rather than focusing on quality service rendered per call. In this regard, standardized and low labor intensity practices are vigorously pursued by management while service employees are pressurized with high levels of workload, rapid pace of work and electronic monitoring in response to meeting performance targets or face disciplinary action, pay cuts or summary dismissal for underperformance. Other reported call center practices that affect employee wellbeing 
Akanji, B. O.

includes high use of scripted dialogue, lack of job discretion, task variety, pressurized monitoring and low managerial support (Gwak, Geong, \& Choi, 2010).

From the foregoing, it has become important to scrutinize stress management interventions (SMIs) that can mitigate the 'stress epidemic' that ostensibly overshadows call center employments. Le Ferve, Matheny, and Kolt (2006, p. 548), broadly defines SMIs as "any purposeful action taken to reduce or alleviate the stress experience by organizational citizens in the execution of their work functions". Established classification of SMIs in literature are primary interventions which focuses on organizational best practices aimed at reducing, modifying or eliminating tensioned work demands that impair health and performance. Secondary interventions mainly enhances person-based approaches of coping with work stressors while tertiary interventions are therapeutic methods aimed at helping employees who already have formed signs and symptoms of illness from stress (Dewe \& O'Driscoll, 2002; Quick \& Quick, 2004). However, concerns articulated by various SMIs scholars are often geared towards criticizing the extent to which secondary and tertiary interventions are still the most popularly adopted stress reductionist approach by employers (Dewe \& O’Driscoll, 2002; Le Ferve, Matheny, \& Kolt, 2006). The approach was challenged by Cousin, MacKay, Kelly, and McCaig (2004) that argued that more primary interventions should be prioritized and made interventions of 'first choice' by employers. Though in the case of call center employments, primary interventions may not suffice for stressors originating from customer stress (e.g. abusive callers) but the obvious reason for prioritizing organizational interventions is that health risk management that focuses on removal or elimination of job stress is far more rewarding than minimizing or treating manifested health damage (Quick, \& Quick, 2004). Thus, the present study seeks to contextualize how work stress and SMIs are perceived in Nigerian call centers.

\subsection{The study context}

Nigeria's telecommunications industry has flourished economically as a result of the Nigerian Civilian Government's decision to deregulate the telecommunications sector in 2001. This paved the way for fully liberalized markets which gave different foreign and local investors corporate opportunities to engage in mobile phone operations popularly known as Global System for Mobile (GSM) telecommunications wireless business in Nigeria (Adebisi, 2011). This brought about creation of call center service jobs which is labor intensive in Nigeria because of the ever increasing customer base of the various GSM mobile network companies operating in Nigeria (Pyramid, 2010). With a population of over 140 million people (Fajana, 2008), the Nigerian mobile telecommunications services was described as one of the fastest growing markets in Africa. Thus, call center activities became strategic points for customer services for the various network providers in Nigeria and grew rapidly across the nation. This centers deals with queries ranging from balance enquiries to customer complaints. Certainly, the diversification of the Nigerian economy from the oil sector to the mobile service industry became a pillar of the nation's economic growth by the creation of call center workplaces and businesses concerned with the distribution of mobile technologies and services. However, it is worth noting that Nigeria is still riddled with national challenges facing its political, economic and social status from the apparent leadership failures, poor infrastructure and corruption that is affecting the nation's industrial development (Ampratwum 2008). This makes Nigeria a fertile field for the present study context.

\section{Methodology}

Epistemologically, the study drew primarily from a phenomenological paradigm for the purposes of sourcing rich qualitative data from real life situations of the study participants. During the interviews, these key informants were not cued in their narrations of all relevant aspect of their call center working conditions. Semi-structured interviews were conducted on site in the two call centers located in Lagos State which is a major commercial city in Nigeria. In order to meet the eligibility criterion, selection of participants was done through judgmental sampling (Saunders, Lewis, \& Thornhill, 2012). Subsequently, names and contact details of most participants were sourced from the author's friends and family and then screened to find out their participatory interest in the research, time in employment and job roles of all interviewees. 19 participants that meet these 
criteria were selected and thereafter, a snowballing sampling was then used to make the total number of the participants. Given the request for confidentiality and anonymity, pseudonyms were used to represent participant's names and their call centers firms. The demographic profiles of all interviewees are presented in the table below:

Table 1

Profile of all the participants

\begin{tabular}{lll}
\hline \multicolumn{1}{c}{ Marital status } & Frequency & $\%$ \\
\hline Single & 19 & 63.3 \\
Married & 10 & 33.3 \\
Divorced & 1 & 3.3 \\
Participants ages & & \\
$30-34$ & 14 & 46.7 \\
$35-39$ & 8 & 26.7 \\
$40-44$ & 5 & 16.7 \\
$45-49$ & 2 & 6.7 \\
50-54 & 1 & 3.3 \\
Educational status & & \\
Undergraduates & 9 & 30 \\
Graduates & 13 & 43.3 \\
Masters degree holder & 8 & 26.7 \\
Number participants & & \\
Call center 1 & 18 & 6 \\
Call center 2 & 12 & 4 \\
Number of Managers & 10 & \\
Number of agents & 20 & \\
Note. Demographic data of study & &
\end{tabular}

The semi-structured interviews were conducted in English and lasted for about 40-60mins with each interviewee. Conversations focused on allowing participants to describe in their own words, experiences of job stress and views about SMIs that can moderate workplace stress. Apart from interviewing call center staffs, the reason for engaging call center team managers was because they represent the middle management. Though a number of similar open-ended questions were asked during the interviews with both service agents and their team managers, however, the main areas of questioning disparity were the attempt made in finding out the understanding of workplace stress at the managerial level. Some notes were also taken during the interview while transcription was carried out thereafter. All the transcribed data were analyzed using thematic analysis (TA) which is a qualitative method useful for "identifying, analyzing and reporting patterns [themes] within data (Braun \& Clarke, 2006). TA offered an accessible and theoretically-flexible approach to analyzing the narrative data. Thus, open coding was utilized as a conceptual devise to tease out and categories commonalities, differences and relationships across data sets. Therefore, emerging themes from the study data were thematically identified primarily at a sematic level of analysis (Boyatzis, 1998). At this level, themes are primarily identified from the surface interpretation and explicit meanings from participants about the topic of under-study.

\section{Findings and Discussion}

The study data provided evidence of what the participants perceived as call center stress within the Nigerian context. In general, a simple framework was developed summarizing the entire views in this regard. Interestingly, within the framework as diagrammatized below, the factors constituting work stress going by the accounts of all service employees were not dissimilar to the established problems that have been reported in call center literature. However, the stress interventions (i.e. moderators) that emerged from findings generated new knowledge on anticipated solutions that were found to be best practices for extenuating service stress and appropriate for enhancing employee well-being. 


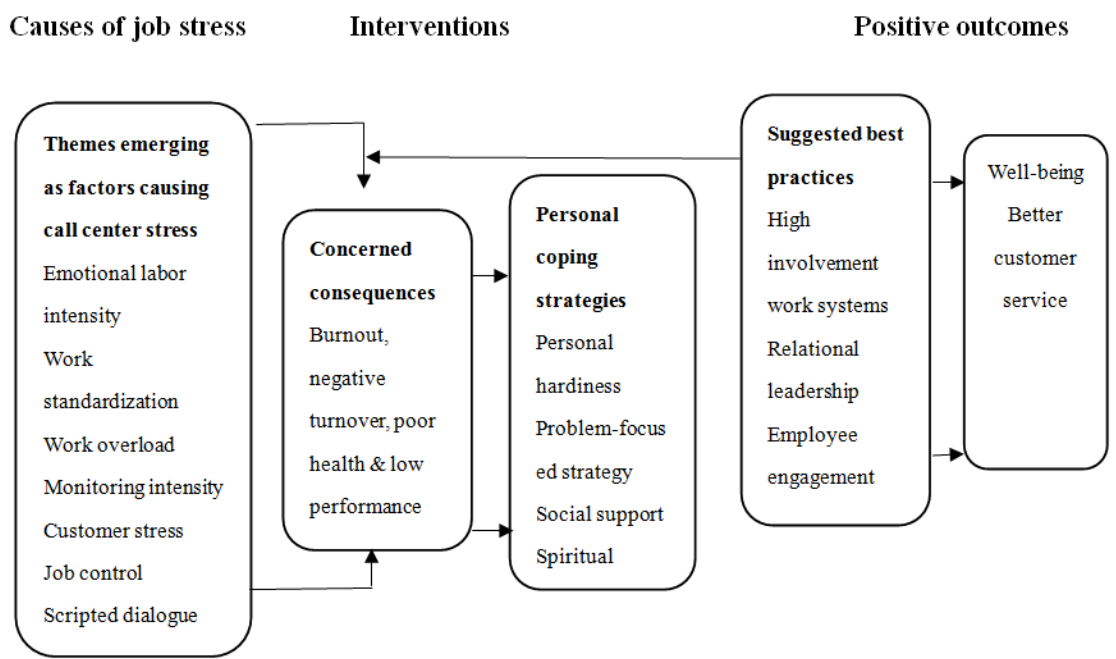

Figure 1: Conceptual findings of study

From the above diagram, the initial findings focused on all participants' accounts of their understanding of stress at work. Views held about work stress experiences within the Nigerian call center employments that did not differ from the conceptual definitions of stress as a stimulus, response-based and interactive proposition in literature. Emphasizes was placed on the fact that the primary causes of stress in call center work were embedded in job characteristics and operational environment. For instance, excerpts from one of the shared views of participants states that:

"The stresses we feel from our work are mostly from job restrictions, managing high call volumes and other general customer service demands" (Joe in Call center 1).

At the managerial level, call center managers expressed concerns of dealing with competing roles and priorities, with differing degrees of demands from senior management. One of the floor managers stated that:

"At my level, my stress concerns is my team performance, making sure that service standard agreement levels are always achieved and meeting every ancillary demands that the company throws at me" (Alicia, Team manager; Contact center 2).

On the whole, the findings revealed differential views of work stress with $33.3 \%$ of participants $(n=10)$ expressing their understanding of stress as stimulus induced as illustrated above in the comments from Joe and Alicia. Furthermore, $23 \%(n=7)$ perceived stress as mental and physical reactions to environmental demands with expressions like “... as a man, my mental and bodily responses depicts if I am stressed depending on work demands" (Joseph, call center 2 agent). However, the rest $43.3 \%(n=13)$ conceptualized stress as occurring when role demands overwhelms the individuals' capacity to meet such service demands. Further, it was gathered in our findings that the various interpretations that all participants held about job stress were influenced by their individual characteristics such as personality traits, age, and sex amongst other demographic factors. Some participants were of the view that personality traits represent distinctive patterns of behavior (including thinking, feelings and beliefs) that is consistent across time and situations.

From the interviews, it was revealed that the variations in opinion about call center stress was significantly premised on cognitive factors such as personal beliefs based on age, employment status, gender and societal context. In addition, some participants perceived to be extroverts due to their sociable and friendly nature on the telephone conceptualized work stress as broadly triggered by external stressors (i.e. stimulus) which requires emotional containment from such employees to still maintain a positive attitude. But some of the introverts explained how difficult these affective adjustments can become. Accordingly, Khoury and Analoui (2009) suggest that this is why employees often react differently to the same set of organizational stressors. Furthermore, 
Parkes (1994), comments that investigation into individual differences is significant for the purposes of clarifying divergent personality traits and their effects in predicting stress outcomes which can in some circumstances be useful in implementing appropriate interventions (Mark, \& Smith, 2008).

However, as the study analysis progressed, some over-arching themes emerged as work stereotypes causing call center stress in Nigeria (see figure 1). For instance, some interviews revealed institutionalized work control systems. The participants confirmed that the heavy reliance of technological surveillance and overt monitoring was the normative tradition employed by managers to "convert labor power to profitable power" (Callaghan, \& Thompson 2001). With regards control frequency, one of the participants said

\begin{abstract}
"My conversation is scripted and remotely monitored so often to the extent that if I miss a line in my compliance script during conversation, I will prefer to go back and repeat the exact words I should have said...the customer can almost guess that I am reading off my computer" (Matthew, an agent in call center 1$)$.
\end{abstract}

A few participants also expressed how customer interactions can adversely affect their wellness in terms of the extreme emotional labor. This is a major feature of call center work involving persistent display of regulated emotions in exchange for wages (Holman 2003). Our interviews unveiled that monitoring practices in the Nigerian call center settings are overly excessive with such extreme emotional demands that require constantly maintaining an imposed friendly customer service disposition (Siong, Mellor, Moore, \& Firth, 2006). This fact has earlier been emphasized by Deery, Roderick, and Janet (2002, p. 39) that call service workers are often targets of customer hostility and abuse. Furthermore, study participants felt that call center operations in Nigeria emphasizes more on structures and systems than employee feelings as most telecoms firms are primarily profit driven.

Work stress was also found to impact family life in Nigeria. Thus, one of the married females narrated that "the most difficult people to deal with are the non-English speaking customers passed through on our language line [...] they won't listen to you [...] I perceive that sometimes I unconsciously transfer some office aggression to my family members at home". This assertion illustrates how work stress can cause work-family conflict (WLC). This resonates with Clark's work-family border crossing theory that presents explanations on how working adults negotiate and manage their work and family roles in order to attain a balance (Clark, 2000). However, Clark identified the complexities involved in managing the borders of both domains due to the fact that employees are seen as border-crossers that are continuously making transitions between both roles of life. For instance, in our present study, participants admitted that spill-over experiences of mental strain transferred into their family life shows the permeability to which their psychological patterns of behavior is sometimes stimulated by over-arching outcomes from stress sources espoused in their call center work. When participants were further scrutinized about the consequences of service practices with regards performance monitoring, one agent answered that "I feel objectified and psychologically drained sometimes". Six other participants also confirmed that though the stereotypical monitoring systems gives predictive capacity and performance directions to managers (Houlihan, 2000) but service agents are most times victims of job stress induced by such monitoring intensity. Furthermore, some other participants commented that job restrictions wielded around their service roles through scripted dialogue metrics barricades the extent to which they can use their discretion. For example, one agent working in call center 1 said:

"Sometimes customer becomes agitated and frustrated when you don't deal with their queries at the first instance [...] but have to transfer them to the relevant department in accordance to compliance procedures. However, I can deal with some of this queries based on my level of work experience but I am restricted because calls are monitored remotely while his job restrictions is the main cause of my job burnouts".

This confirms that the traditional practices of strict monitoring and intense use of scripted processes designed to interact with customers reduces work latitude and increase burnout which in turn affects the 
Akanji, B. O.

competent levels of agents (Spring, \& Jackson, 2006).

One-third of the participants further confirmed that the scripted dialog tradition of call center work makes the job monotonous, boring and strenuous. Other stressors that were raised by participants included psychological strain from fear of not meeting targets, job insecurity and other severe sanctions that can cause mental detachment from their service roles. On turnover, most participants' shared similar views were: "I can never think of leaving my job with this high rate of unemployment in Nigeria [...] I have learnt to endure and ensure I fulfil the minimum service standards to secure my job". Another participant said "I have developed a sense of hardiness against the stress tides in Nigeria". It is worthy of note that the majority of the Nigerian population (estimated 70\%) lives below the poverty line arising from Nigeria's leadership failures, corruption, high inflation rates, disturbing unemployment rates, economic mismanagement and other plethora of reverses that characterizes a nation in crisis. This is the reason why working Nigerians in gainful employment hold on tightly to their jobs even in the face of adverse working conditions caused by the minimal enforcement of labor laws (Anyim, Ikemefuna, \& Mbah, 2011).

With regarding to coping with stress, some participants narrated that 'personal hardiness' are traits that have been developed as a psychological and physical coping resource. Hardiness is commonly taken to be a nature in which individuals' seek to generate positive self-evaluation that produces positive emotions about the future even in the face of adversity (Greenhaus, \& Powell, 2006). Nigerians have been known to be born survivors no matter the pressures of life encountered. Study participants also narrated that individual coping strategies were still their best options of relieving themselves from the extreme pressures they encounter during service interaction. This is given to the fact that primary stress management interventions are still minimally recognized in Nigerian employments (Mordi, Mmieh, \& Ojo, 2013).

Few participants advised that they adopt the problem-focused strategy like requesting transfer from being a call center staff to the back office when their call center roles becomes overwhelmingly stressful to bear. But majority of the participants advised they lean on social support by relying on managers to provide necessary assistance to struggling agents. According to some agents, a common supervisory support is adhering to the policy of escalating difficult calls to line managers on duty. This policy provides needed guidance in call time control and lessens the emotional burden of customer stress on floor agents. Though one of the managers expressed concerns of this policy because most often, it set superiors at the receiving end of such difficult calls. Some other agents shared views that they cope with stress in an emotionally positive thinking manner (Lazarus, \& Folkman, 1984). For instance, some participants claim to engaged in positive thinking strategy by suggesting that their spiritual beliefs in a 'Celestial God' gives them signs of relief from the stress of life. Specifically, one participant said "I am a Christian and God has been my source of protection and relief from emotional stress". Also, another agent advised that been a Muslim, his employers allow staffs to hold their traditional fifteen minutes Friday prayers in a room provided around the call center building.

This finding resonates with a previous study by Mordi et al. (2013) that found Nigerians to be religious with various degrees of beliefs shaping peoples' way of life in a positive sense. Though the overall views of some participants is that most of this secondary interventions are curative in nature and falls short of addressing the contextual and structural challenges within the Nigerian context. Furthermore, some of the informants were of the opinion that their managers are not sufficiently trained in understanding the implications of stress in the workplace to enable them acknowledge the need for adopting primary interventions in addressing workplace stress problems. Although five managers interviewed in present study held a defensive view of experiencing higher stress levels in managing their respective call center teams and assigned more job task such as tracking the number of calls per agent, abandonment call time, agent's wrap time and achieving all other key performance indicators (KPIs). The managers voiced out their minds that they are trained to be task oriented in their approach in managing team productivity and workplace risk assessment. One manager explained that: 
A study on occupational stressors and effective stress management interventions from a call center perspective

"Because my managerial performance is heavily measured by quantitative metrics, I carry out my team's health risk assessment based on the prescribed computer generated questionnaires that agents fill and return for statistical computations".

However, some agents were of the view that this standardized intervention was insufficient too because it often fails to address the substantive issues aimed at eliminating and reducing the intensity of the number of call center stressors.

Given the prevailing circumstances, agents conveyed arguments that primary stress management interventions are the best solutions for better performance standards and workplace wellbeing in Nigeria. Study participants expressed desires for best practices to converge at more robust 'prevention is better than cure' models. Some themes emerged as recommendations that can effectively moderate call center stress sources and consequences (see figure 1). Thus, solutions such as introducing high involvement work systems, shared leadership, employee engagement and work-wife balance practices were described as proactive ways of promoting employee and organizational health standards in call centers. In respect to high involvement systems, participants of study expressed views that they would prefer a call center culture that fosters collaboration and mutual support that can engender agents to do their jobs effectively through the instrumentality of job autonomy. To this effect, high involvement work practices that emphasizes on active participation of employees in work processes through self-managed teams was suggested to be desirable for employee well-being rather than short-termism practices that breed high rates of absenteeism, turnover, anxiety and burnout. This recommendations made by Nigerian call center workers suggest that high involvement work systems could act as a proactive model against organizational stress designed to treat people as organizational resources in which to invest, rather than costs to be controlled (Mendelson, Turner, \& Barling, 2011).

Further, some participants also recommended that effective SMI will be better achieved if Nigerian call center managers are more relational in leadership approach and further focus on employee engagement. This approach was viewed as producing a fit in interpersonal relationships between call center superiors and subordinates. Accordingly, Wallace, Eagleson, and Waldersee (2000) suggested that HR practices in call centers that aims at delivering excellent service will be better achieved through supportive management. Thus, some call center agents suggested relationship leadership presents management practices that will empower Nigerian agents to partake in decision-making processes which will subsequently decrease job-related stress and increase work satisfaction. To this end, participative leadership approaches have been found to impact positively on employee engagement that fosters organizational citizenship that can motivate positive outcomes at both the employee and firm level (Robertson, \& Cooper, 2006). This last recommendation was in the area of promoting work-life balances policies. Some of the participants that were married signified how strain based outcomes originating from call center stress could act as primary cause of work-family conflict. This was confirmed by the quantitative study of Kinman, (2009) that the continuous display of high emotional regulation in customer service roles may result in strain-based spill-overs from work to other non-work domains which may manifest in various forms of signs and symptoms of sleeplessness, debilitations, aggression, social withdrawal, health impairment and turnover intentions.

Further, few of the married participants in our study commented that the high level of occupational stress in their service roles interfere with their parental responsibilities especially when they work night shifts and are compelled to engage services of extended family members and paid house helps for child care support. This is because the Nigerian culture is perceived to be a collectivist culture that places more value on family ties. However, work-life balance presents a significant social consciousness that the economic, family and social life of an adult worker should present less competing priorities but rather complementary elements of a full life (Manfredi, \& Holliday, 2004). Findings emerged for call center management to implement family-friendly policies such as better flexi time, job sharing, compressed hours, and childcare facilities among other working practices. Married participants suggested that the recognition of these policies will in return strengthen employee engagement and call center productivity. 


\section{Conclusions and area for future research}

This study has shown that job stress in call center work is a ubiquitous phenomenon with similar characteristics, antecedents and impact on human resource. Evidently, the present research has shown that the context of job stress in call center work existing within a developing nation of Nigeria share similarities with challenges often identified in call centers established in developed countries. For instance, this study presented Nigerian service workers as defining work stress from the three different theoretical perspectives reviewed in literature. Study findings also revealed participants using various individual coping strategies to mitigate the harsh effects of stress encountered during service encounters. Findings also revealed participants expressing the need for their call organizations to adopt proactive stress management practices instead of leaving individual employee to cope with the various levels of call center stress being faced on a daily basis. Thus, the practical implication of the study is for management and HR managers to consider aspects of the working conditions that are identified as stressful within the Nigerian context with the aim of finding lasting solutions. For instance, best practices suggested by participants should be implemented to make call center work more tolerable. Call center agents can be given more work autonomy while using monitoring processes to develop skills variety rather than for disciplinary purposes. In addition, work-life balances policies should be adopted at the behest of agents with family responsibilities. One of the limitations of the study is the relatively small sample size of participants drawn from two call centers in Nigeria. Additionally, the study concentrated on only one State (i.e. Lagos) of Nigeria out of the numerous contact center spreading across various States in the country. This makes the findings less generalizable. However, future quantitative data can be collected to test the validity of this qualitative study.

\section{References}

Adebisi, S. (2011). GSM marketing services providers operations and customer satisfaction in Nigeria: An empirical Investigation. Acta Universitatis Danubius Economica, 7(1), 1-20.

Ackfeldt, A., \& Malhotra, N. (2012). Revisting the role stress-commitment relationship: Can managerial interventions help? European Journal of Marketing, 47(3), 1-37.

Ampratwum, E. F. (2008). The fight against corruption and its implications for development in developing and transition economies. Journal of Money Laundering Control, 11(1), 76-87. http://dx.doi.org/10.1108/13685200810844514

Anyim, F. C., Ikemefuna, C. O., \& Mbah, S. E. (2011). Human resource management in Nigeria under a globalised economy. International Journal of Economics and Management Sciences, 1(4), 1-11.

Boyatzis, R. E. (1998). Transforming qualitative information: Thematic analysis and code development. Thousand Oaks, CA Sage.

Braun, V., \& Clarke, V. (2006). Using thematic analysis in psychology. Qualitative Research in Psychology, 3(2), 77-101. http://dx.doi.org/10.1191/1478088706qp063oa

Budhwar, P. S., Varma, A., Malhotra, N., \& Mukherjee, A. (2009). Insights into the Indian call center industry: can internal marketing help tackle high employee turnover? Journal of Services Marketing, 23(5), 351-362. http://dx.doi.org/10.1108/08876040910973459

Callaghan, G., \& Thompson, P. (2001). Edwards revisited: technical control and call centers. Economic and Industrial Democracy, 22(1), 15-37. http://dx.doi.org/10.1177/0143831X01221002

Choi, S., Cheong, K., \& Feinberg, R. A. (2012). Moderating effects of supervisor support, monetary rewards, and career paths on the relationship between burnout and turnover intentions in the context of call center. Managing Service Quality, 22(5), 492-516. http://dx.doi.org/10.1108/09604521211281396

Clark, S. C. (2000). Work/family border theory: A new theory of work/family balance. Human Relations, 53(6), 747-770. http://dx.doi.org/10.1177/0018726700536001

Cox, T. (1978). Stress. London, MacMillian Press. http://dx.doi.org/10.1007/978-1-349-15953-6

Cousin, R., MacKay, C. J., Kelly, P. J., \& McCaig, R. H. (2004). Management standards' and work-related stress in the UK: practical development. Work and Stress, 18(2), 113-36. 
A study on occupational stressors and effective stress management interventions from a call center perspective http://dx.doi.org/10.1080/02678370410001734322

Das, D., Dhawadkar, R., \& Brandes, P. (2008). The importance of being 'Indian': Identity centrality and work outcomes in an off-shored call center in India. Human Relations, 61(11), 1499-1530. http://dx.doi.org/10.1177/0018726708096636

Deery, S., Roderick, I., \& Janet, W. (2002). Work relationships in telephone call centers: Understanding emotional exhaustion and employee withdrawal. Journal of Management Studies, 39(4), 471-496. http://dx.doi.org/10.1111/1467-6486.00300

Dewe, P., \& O'Driscoll, M. (2002). Stress management interventions: what do managers actually do? Personnel Review, 31(2), 143-165. http://dx.doi.org/10.1108/00483480210416847

Fajana, S. (2008). The Nigerian informal economy: Instigating decent work and pay, and national development through unionization. Employee Relations, 30(4), 372-390.

http://dx.doi.org/10.1108/01425450810879358

Garson, B. (1988). The electronic sweatshop: How computers are transforming the office of the future into the factory of the past. New York, Simon and Schuster Publishers.

Grandey, A., Dickter, D., \& Sin, H. P. (2004). The customer is not always right: Customer verbal aggression towards service employees. Journal of Organizational Behavior, 25(3), 397-418. http://dx.doi.org/10.1002/job.252

Greenhaus, J. H., \& Powell, G. N. (2006). When work and family are allies: A theory of work-family enrichment. Academy of Management Review, 31, 72-92. http://dx.doi.org/10.5465/AMR.2006.19379625

Gawk, S., Geong, K., \& Choi, S. (2010). Study on the effects of the job burnout on the customer orientation, job satisfaction, and turnover intention of customer service representatives at customer centers. Korean Management Review, 39(3), 541-76.

Hoschchild, A. (1983). The managed heart: Commercialization of human feelings. University of California Press, Berkeley, CA.

Holman, D. (2003). Phoning in sick? An overview of employee stress in call center. Leadership and Organizational Development Journal, 24(3), 123-130. http://dx.doi.org/10.1108/01437730310469543

Houlihan, M. (2000). Eyes wide shut? Querying the depth of call center learning. Journal of European Industrial Training, 24(2), 228-240. http://dx.doi.org/10.1108/03090590010321197

Khoury, G., \& Analoui, F. (2009). How Palestinian managers cope with stress. Journal of Management Development, 29(3), 282-291. http://dx.doi.org/10.1108/02621711011025795

Kinman, G. (2009). Emotional labor and strain in front-line service employees: does mode of delivery matter? Journal of Managerial Psychology, 24(2), 118-135. http://dx.doi.org/10.1108/02683940910928847

Lazarus, R. S., \& Folkman, S. (1984). Stress: Appraisal and coping. New York, Springer.

Le Fevre, M., Matheny, J., \& Kolt, G. S. (2003). Eustress, distress, and interpretation in occupational stress. Journal of Managerial Psychology, 18(7), 726-744. http://dx.doi.org/10.1108/02683940310502412

Manfredi, S., \& Holliday, M. (2004). Work-life balance: An audit of staff experience at Oxford Brookes University. The Center of Diversity Policy Research, Oxford Brookes University.

Mark, G. M., \& Smith, A. P. (2008). Stress models: A review and suggested new direction. In J. Houdmont \& S. Leka (Eds.), Occupational health psychology, European perspectives on research, education and practice (Vol. 3, pp. 111-144). Nottingham University Press.

Mendelson, M. B., Turner, N., \& Barling, J. (2011). Perceptions of the presence and effectiveness of high involvement work systems and their relationship to employee attitudes: A test of competing models. Personnel Review, 40(1), 45-69. http://dx.doi.org/10.1108/00483481111095519

Morris, J. A., \& Feldman, D. C. (1996). The dimensions, antecedents, and consequences of emotional labor. Academy of Management Review, 21(4), 986-1010.

Mordi, C., Mmieh, F., \& Ojo, S. I. (2013). An exploratory study of managers' perspective of work-life balance: a case study analysis of the Nigerian banking sector. Thunderbird International Business Review, 55(1), 55-75. http://dx.doi.org/10.1002/tie.21523

Mukherjee, A., \& Malhorta, N. (2006). Does role clarity explain employee-perceived service quality? A study of antecedents and consequences in call centers. International Journal of Service Industry Management, 
Akanji, B. O.

17(5), 444-473. http://dx.doi.org/10.1108/09564230610689777

Parkes, K. (1994). Personality and coping as moderators of work stress processes: models, methods and measures. Work and Stress, 8, 110-129. http://dx.doi.org/10.1080/02678379408259984

Pyramid research. (2010). Retrieved from http://www.pyramidresearch.com

Quick, J. C., \& Quick, J. D. (2004). Healthy, happy, productive work: A leadership challenge. Organizational Dynamics, 33(4), 329-337. http://dx.doi.org/10.1016/j.orgdyn.2004.09.001

Rasila, H. (2012). Attitudes towards problems in the physical working environment: Case contact center. Journal of Corporate Real Estate, 14(2), 94-104. http://dx.doi.org/10.1108/14630011211261696

Robinson, G., \& Morley, C. (2006). Call center management: Responsibilities and performance. International Journal of Service Industry Management, 17(3), 284-300. http://dx.doi.org/10.1108/09564230610667122

Robertson, I. T., \& Cooper, C. L. (2006). Full engagement: The integration of employee and psychological well-being. Leadership and Organizational Development Journal, 31(4), 324-336. http://dx.doi.org/10.1108/01437731011043348

Saunders, M. K., Lewis, P., \& Thornhill, A. (2012). Research methods for business students (6th ed). London, Prentice Hall UK.

Selye H. (1974). Stress without distress. New York: New American Library.

Siong, Z. M., Mellor, D., Moore, K. A., \& Firth, L. (2006). Predicting intention to quit in the call center industry: does the retail model fit? Journal of Managerial Psychology, 21(3), 231-243. http://dx.doi.org/10.1108/02683940610659579

Sprigg, C. A., \& Jackson, P. R. (2006). Call centers as lean service environments: Job-related strain and the mediating role of work design. Journal of Occupational Health Psychology, 11(2), 197-212. http://dx.doi.org/10.1037/1076-8998.11.2.197

Taylor, P., \& Bain, P. (1999). An assembly line in the head: work and employee relations in the call center. Industrial Relations Journal, 30, 101-117. http://dx.doi.org/10.1111/1468-2338.00113

Vikola, M., \& Nikolaou, I. (2005). Attitudes towards organizational change: what is the role of employee' stress and commitment. Employee Relations, 27(2), 160-174. http://dx.doi.org/10.1108/01425450510572685

Wallace, C. M., Eagleson, G., \& Waldersee, R. (2000). The sacrificial HR strategy in call centers. International Journal of Service Industry Management, 11(2), 174-184. http://dx.doi.org/10.1108/09564230010323741 